\title{
The Number of Lymph Nodes Harvested in Open and Laparoscopic Colo-Rectal Surgery: A Comparative Study
}

\author{
Ahmed Morad, MD; Tarek Youssef MD, MRCS; FACS, Ahmed Aly MD, FACS \\ Department of General Surgery, Ain Shams University, Cairo, Egypt
}

Background: The prognostic significance of identifying lymph node metastasis in cancer colon and rectum is of great importance. There is an association between the number of lymph nodes in the resection specimen and survival particularly in node negative cancer.

Aim: This study aims at comparing the number of lymph nodes harvested in open and laparoscopic colorectal surgery for colorectal cancer.

Patients and methods: This is a prospective study involving 40 patients with left sided colonic cancer and rectal cancer. The patients were divided into equal 4 groups:

Group (1A): patients who underwent open left hemicolectomy or sigmoidectomy

Group (1B): Patients who underwent laparoscopic left hemicolectomy or sigmoidectomy

Group (2A): Patients who underwent open anterior or low anterior resection

Group (2B): Patients who underwent laparoscopic anterior or low anterior resection

Histopathological examination of the retrieved specimens and assessment of the number of lymph nodes was done. Data was compared among different groups.

Results: In laparoscopic procedures, more lymph nodes were retrieved than in open surgery with statistically significant difference ( $p$-value 0.019 ). The mean SD of number of lymph nodes retrieved was 14 in the laparoscopic group versus 10.5 in the open group.

Conclusion: Laparoscopic resection of left sided colorectal cancer yields adequate samples of lymph nodes number that are comparable to those obtained by open surgery.

Key words: Lymph node harvest, colorectal cancer, laparoscopic resection.

\section{Introduction}

The number of harvested lymph nodes (LNs) required to allow accurate staging of colorectal cancer is a matter of debate..$^{1,2}$

The exact number of LNs that should be removed on surgery are affected by both surgeon and the method of pathologic examination. ${ }^{3}$

Goldstein et al., ${ }^{2}$ suggested harvesting as many lymph nodes as possible during curative resection for colon cancer because accurate staging of colorectal cancer depends on adequate retrieval and accurate reporting of LNs in the specimen.

Also it was found that the number of lymph nodes itself has prognostic value in predicting outcome, and that removal of 18 lymph nodes or more improved survival, particularly for node negative patients. 4,5

In a systematic review examined whether the number of lymph nodes retrieved following colon resection was related to survival by studying 61.371 patients, there was a positive association between the number of lymph nodes examined and survival in stage II and III colon cancer patients. ${ }^{6}$

The college of American pathologists recommends at least 12 lymph nodes be sampled in a colorectal cancer resection specimen. Based on such statement, there has been a push to use the number of retrieved lymph nodes as an indicator of quality of care and hospital level.?

Many factors affect the number of lymph nodes examined including patients age, tumor location, tumor size, extent of surgical resection, BMI and pathology techniques. ${ }^{8,9}$

It is evident now that laparoscopy on colorectal cancer offers the opportunity for meticulous dissection of the mesocolon and mesorectum with 
a true no-touch technique. ${ }^{10,11}$

Data concerning lymph nodes numbers retrieval after laparoscopic colorectal surgery and if it is different from open surgery are poor.

\section{Aim of the study}

This study aims to compare the number of lymph nodes harvested during both open and laparoscopic colorectal surgery for colorectal carcinoma, thus to assess the quality of laparoscopic colorectal surgery in achieving adequate resection specimens as regards lymph nodes' number.

\section{Patients and methods}

- Study design: This study is a prospective comparative study carried on in Ain Shams University hospitals between December 2014 \& December 2016.

- Study population: 40 patients with colorectal carcinoma underwent left hemicolectomy, sigmoidectomy and anterior or low anterior resection.

Patients were reviewed in two groups: (group 1) represented patients who underwent left hemicolectomy and/or sigmoid colectomy; (group 2) represented patients who underwent anterior resection or low anterior resection (each group 20 patients).

Each group was further subdivided into two equal subgroups: (Group A) represented patients who underwent open colectomy; (Group B) represented patients who underwent laparoscopic colectomy.

Thus; the study included four subgroups: Group 1A representing those who underwent open left hemi-colectomy; or sigmoidectomy Group 1B representing those who underwent laparoscopic left hemi-colectomy; or sigmoidectomy Group 2A representing those who underwent open anterior or low anterior resection; and Group 2B representing those who underwent laparoscopic anterior or low anterior resection.

The patients recruited in the study were generally fit for open and laparoscopic surgery and had colorectal cancer within a resectable stage i.e: not locally advanced.

Patientsweredistributed byrandomcomputerization method. Both groups were compared as regards the number of lymph nodes retrieved within the specimen excised intraoperatively.

\section{All patients were subjected to the following:}

- Preoperative assessment:

1. Full labs and tumor markers: Carcinoembryonic antigen (C.E.A.).

2. Colonoscopy and biopsy from any suspicious pathology within the colon

3. Pelvi-abdominal computed tomography (P.A.C.T.) with contrast

4. Age, gender, BMI, tumor sizes and sites were recorded and compared between open and laparoscopic group.

- Intraoperative assessment:

General assessment of the abdomen was for extracolonic nodules, enlarged lymph nodes, malignant ascites or peritoneal deposits followed by adopting the no-touch technique for dealing with the tumor i.e. ligating the main vessels near their origin followed by clamping the margins of the specimen before disturbing the tumor if possible. Otherwise, the traditional methods of attacking the tumor first were adopted.

- Postoperative assessment:

Included histopathological assessment of the retrieved specimen also the number of lymph nodes retrieved within the specimen and the degree of their infiltration.

\section{Positioning of the patient}

- For lesions involving the left colon, the patient was positioned supine.

- For lesions involving the sigmoid colon, rectum and anal canal, the patient was positioned in the modified lithotomy position (Lloyd Davis position).

In the laparoscopic group, the surgeon stood on the right side of the abdomen with the camera man on the same side of the surgeon and the second assistant on the opposite side.

The monitor was placed on the same side of the lesion facing the surgeon. Initial access to the abdomen was achieved by the open (Hasson's) method at the umbilical region unless there were marked adhesions where the left hypochondrium (Palmer`s point) was used. 


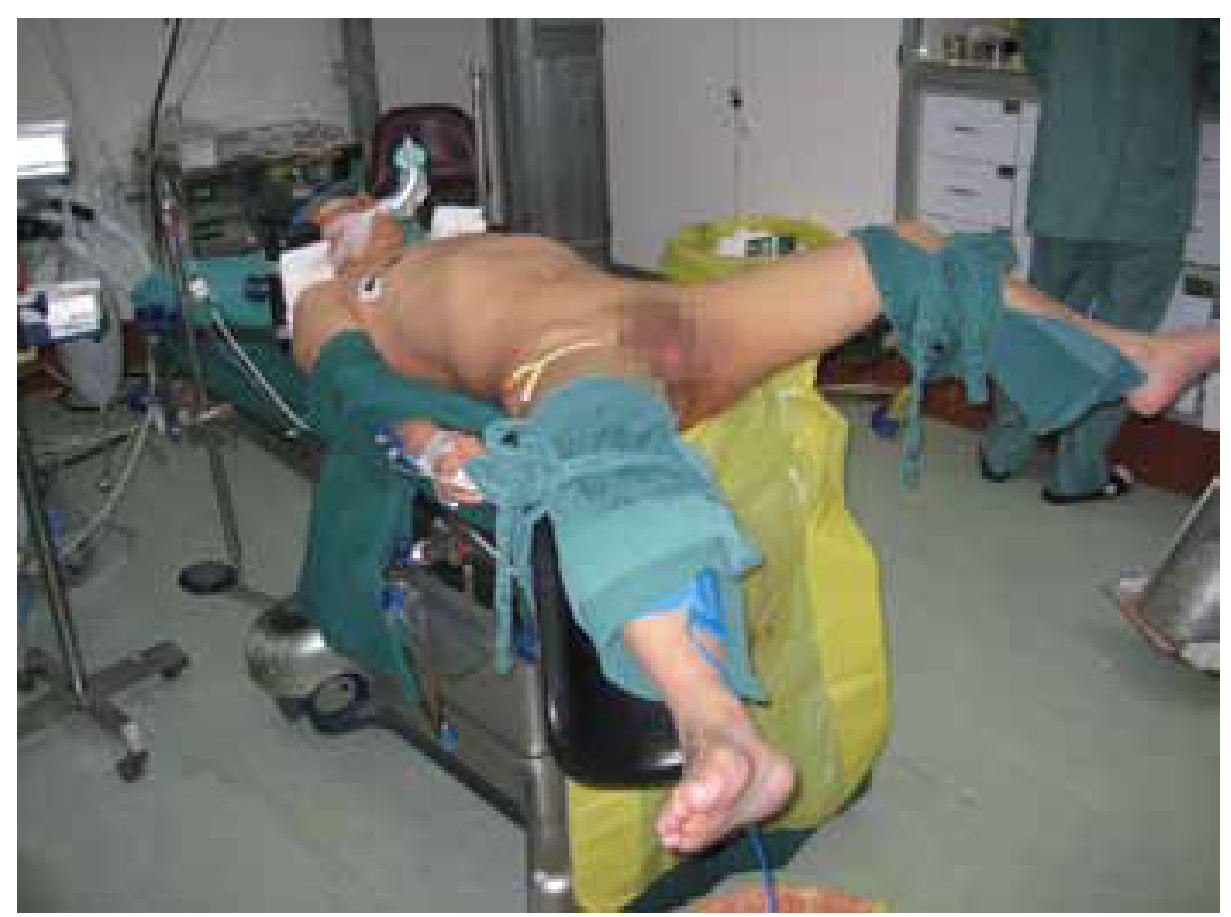

Fig 1: Positioning of the patient in laparoscopy.

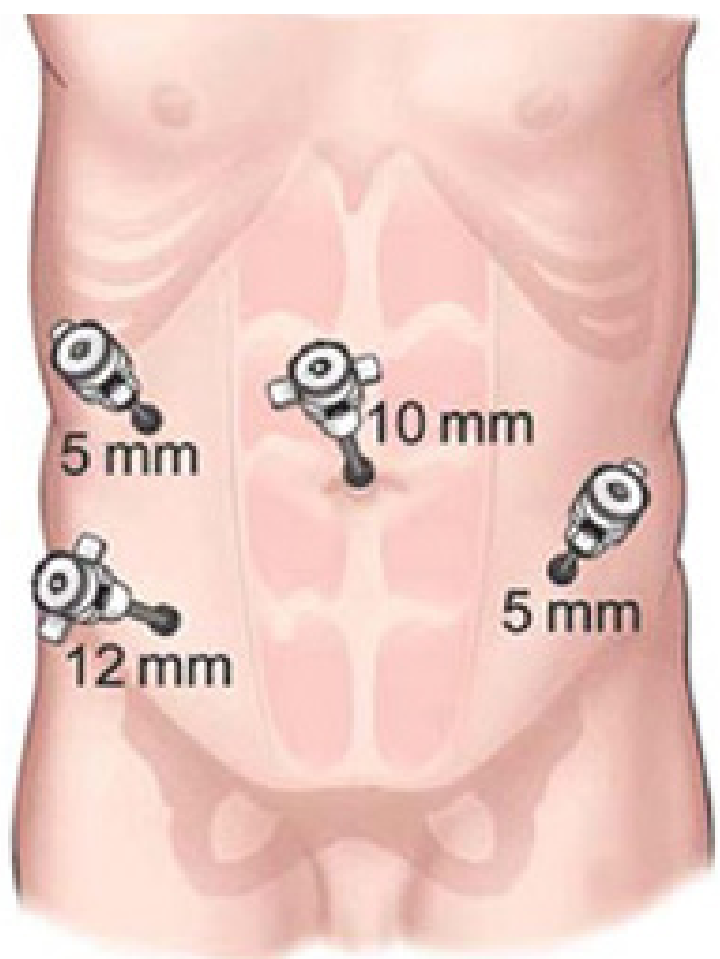

Fig 2: Position of ports for laparoscopic colectomy. 


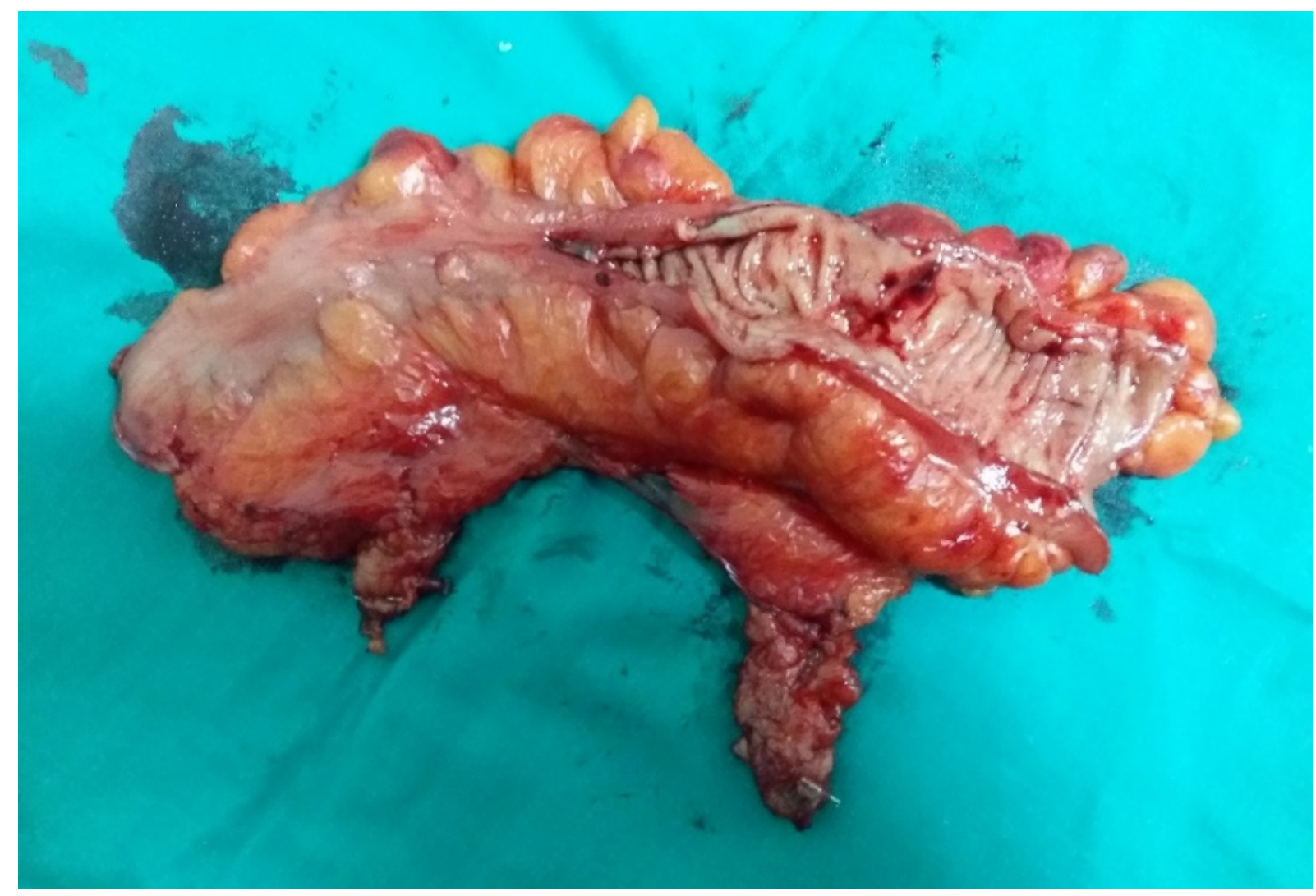

Fig 3: Sigmoid colectomy specimen showing malignant ulcer with high ligation of the IMA for adequate lymph node retrieval.

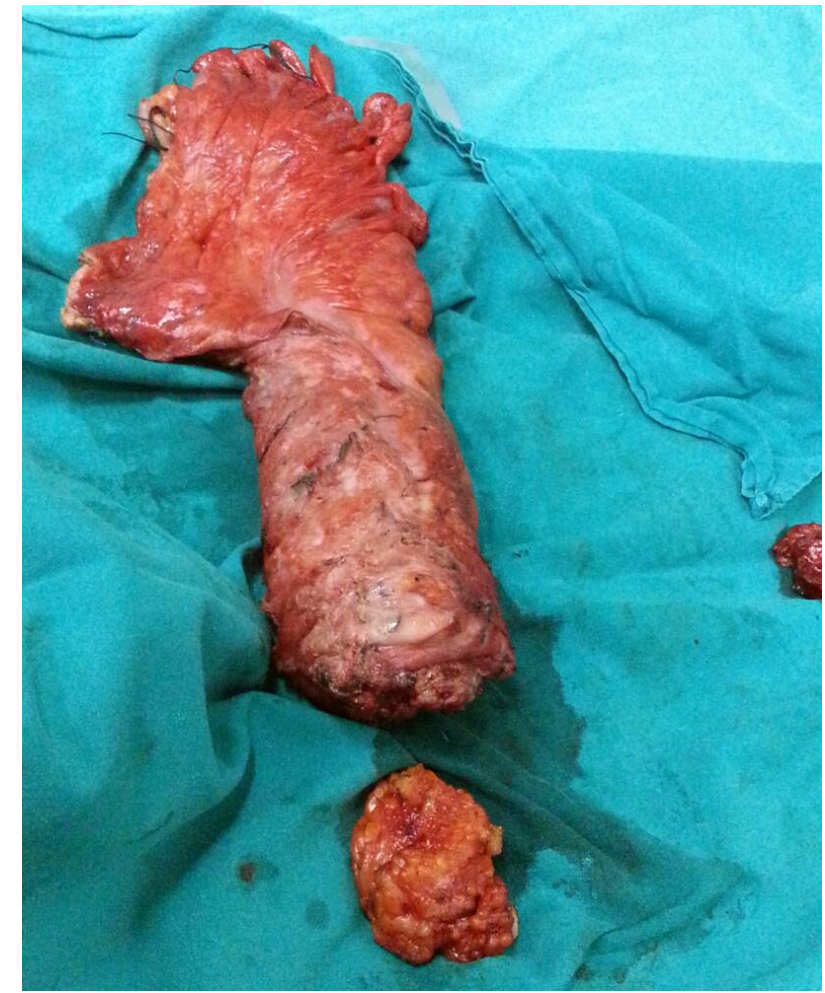

Fig 4: Anterior resection specimen with total mesorectal excision. 


\section{Results}

40 patients with Lt. sided colorectal cancer 26 $(65 \%)$ male and 14 (35\%) female with mean age $52 \pm 10.3$ years were included in this study (Table 1).

Table 1: Age, gender, BMI, tumor sites and tumor sizes in both open and laparoscopic groups

\begin{tabular}{|c|c|c|c|c|}
\hline Variable & $\begin{array}{l}\text { Open group }(1 A, 2 A) \\
n=20\end{array}$ & $\begin{array}{c}\text { Laparoscopic group } \\
\left(\begin{array}{c}1 \mathrm{~B}, 2 \mathrm{~B}) \\
\mathrm{n}=\mathbf{2 0}\end{array}\right.\end{array}$ & \multicolumn{2}{|c|}{ P value } \\
\hline Age (years) & $52 \pm 11.9$ & $53 \pm 13.2$ & 0.8 & NS \\
\hline \multicolumn{5}{|l|}{ Gender } \\
\hline Female & 8 & 6 & 0.5 & NS \\
\hline Male & 12 & 14 & 0.99 & NS \\
\hline BMI $\left(\mathrm{kg} / \mathrm{m}^{2}\right)$ & $28.7 \pm 6.2$ & $27.9 \pm 8.2$ & 0.24 & NS \\
\hline Tumor size $(\mathrm{cm})$ & $3.9 \pm 8.2$ & $4.4 \pm 7.6$ & 0.51 & NS \\
\hline \multicolumn{5}{|l|}{ Tumor site } \\
\hline Lt. colon & 4 & 3 & 0.51 & NS \\
\hline Sigmoid & 6 & 7 & 0.42 & NS \\
\hline Rectum & 10 & 10 & 0.3 & NS \\
\hline
\end{tabular}

NS: non significant

Table 2: Comparison between the number of lymph nodes in both open and laparoscopic subgroups

\begin{tabular}{|c|c|c|c|c|c|c|}
\hline \multirow{3}{*}{$\begin{array}{l}\text { Number of } \\
\text { lymph nodes }\end{array}$} & \multicolumn{4}{|c|}{ Groups } & \multirow{2}{*}{\multicolumn{2}{|c|}{ Chi-square test }} \\
\hline & \multicolumn{2}{|c|}{ Group (1A,2A) } & \multicolumn{2}{|c|}{ Group (1B,2B) } & & \\
\hline & No. & $\%$ & No. & $\%$ & $\times 2$ & p-value \\
\hline$<12$ & 11 & 55 & 7 & 35 & & \\
\hline$>=12$ & 9 & 45 & 13 & 65 & 1.616 & 0.204 (NS) \\
\hline Total & 20 & 100 & 20 & 100 & & \\
\hline
\end{tabular}

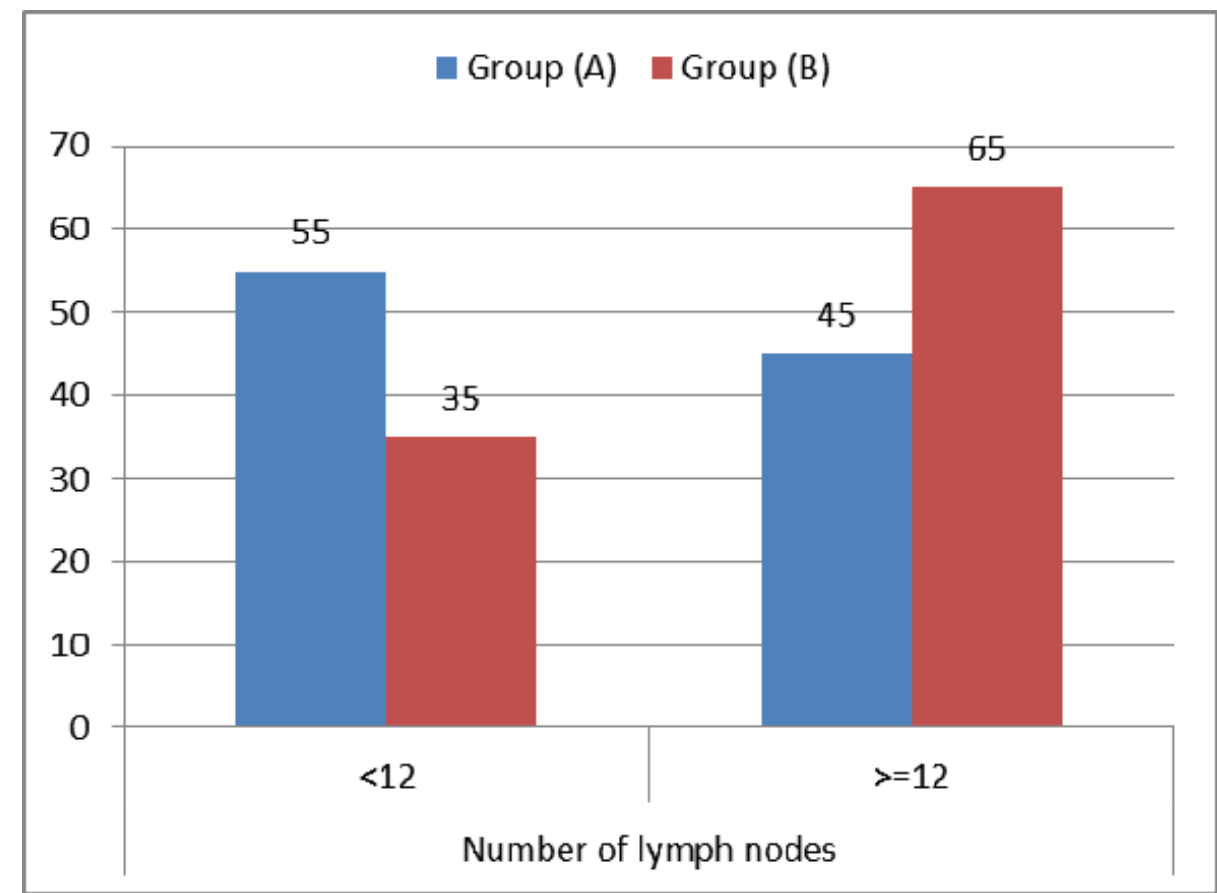

Graph 1: A comparison between the number of lymph nodes in both open and laparoscopic groups taking the number of 12 lymph nodes as a reference point (A): open colectomy, (B): laparoscopic colectomy. 
In Table $\mathbf{2}$ taking the recommended number of 12 lymph nodes within the specimen as an indicator of its adequacy, it was obvious that there was no significant difference between the subgroups as regards the number of lymph nodes retrieved with a p-value of 0.204 which is statistically nonsignificant.

Table 3: Comparison between the numbers of lymph nodes in each one of the four groups also taking the number of 12 lymph nodes as a reference point

\begin{tabular}{|c|c|c|c|c|c|c|}
\hline \multirow{3}{*}{ Groups } & \multicolumn{4}{|c|}{ Number of lymph nodes } & \multirow{2}{*}{\multicolumn{2}{|c|}{ Chi-square test }} \\
\hline & \multicolumn{2}{|c|}{$<12$} & \multicolumn{2}{|c|}{$>=12$} & & \\
\hline & No. & $\%$ & No. & $\%$ & $\times 2$ & p-value \\
\hline Group (1A) & 6 & 60 & 4 & 40 & & \\
\hline Group (1B) & 3 & 30 & 7 & 70 & & \\
\hline Group (2A) & 5 & 50 & 5 & 50 & 2.020 & 0.568 (NS) \\
\hline Group (2B) & 4 & 40 & 6 & 60 & & \\
\hline Total & 18 & 45 & 22 & 55 & & \\
\hline
\end{tabular}

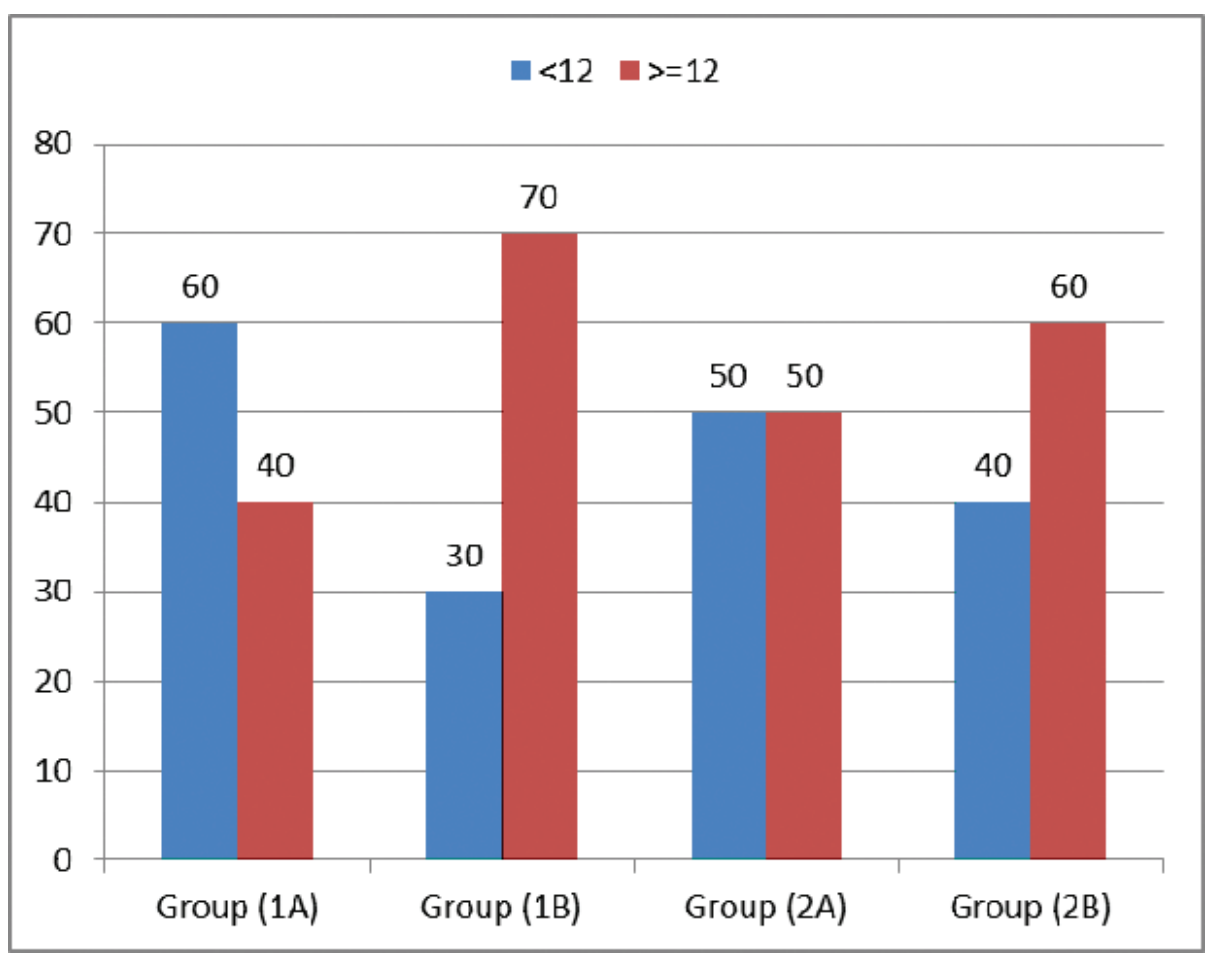

Graph 2: A more detailed comparison between the numbers of lymph nodes in each one of the four groups also taking the number of 12 lymph nodes as a reference point.

In Table 3 a closer view was taken where the percentage of each sub-group was made obvious. It was clear, for another time, that there was no significant difference between the open procedure when being compared to its counterpart laparoscopic one taking the number of 12 lymph nodes as a reference point. This was shown statistically by the $p$-value 0.568 . 
Table 4: Comparison between the mean number of lymph nodes retrieved in both open and laparoscopic groups

\begin{tabular}{|c|c|c|c|c|}
\hline \multirow{2}{*}{ Groups } & \multicolumn{2}{|c|}{ Number of lymph nodes } & \multicolumn{2}{|c|}{ t-test } \\
\hline & Mean & Std. Deviation & $\mathbf{t}$ & p-value \\
\hline Group $(1 \mathrm{~A}, 2 \mathrm{~A})$ & 10.50 & 4.85 & \multirow{2}{*}{-2.454} & \multirow{2}{*}{$0.019(S)$} \\
\hline Group $(1 \mathrm{~B}, 2 \mathrm{~B})$ & 14.00 & 4.14 & & \\
\hline
\end{tabular}

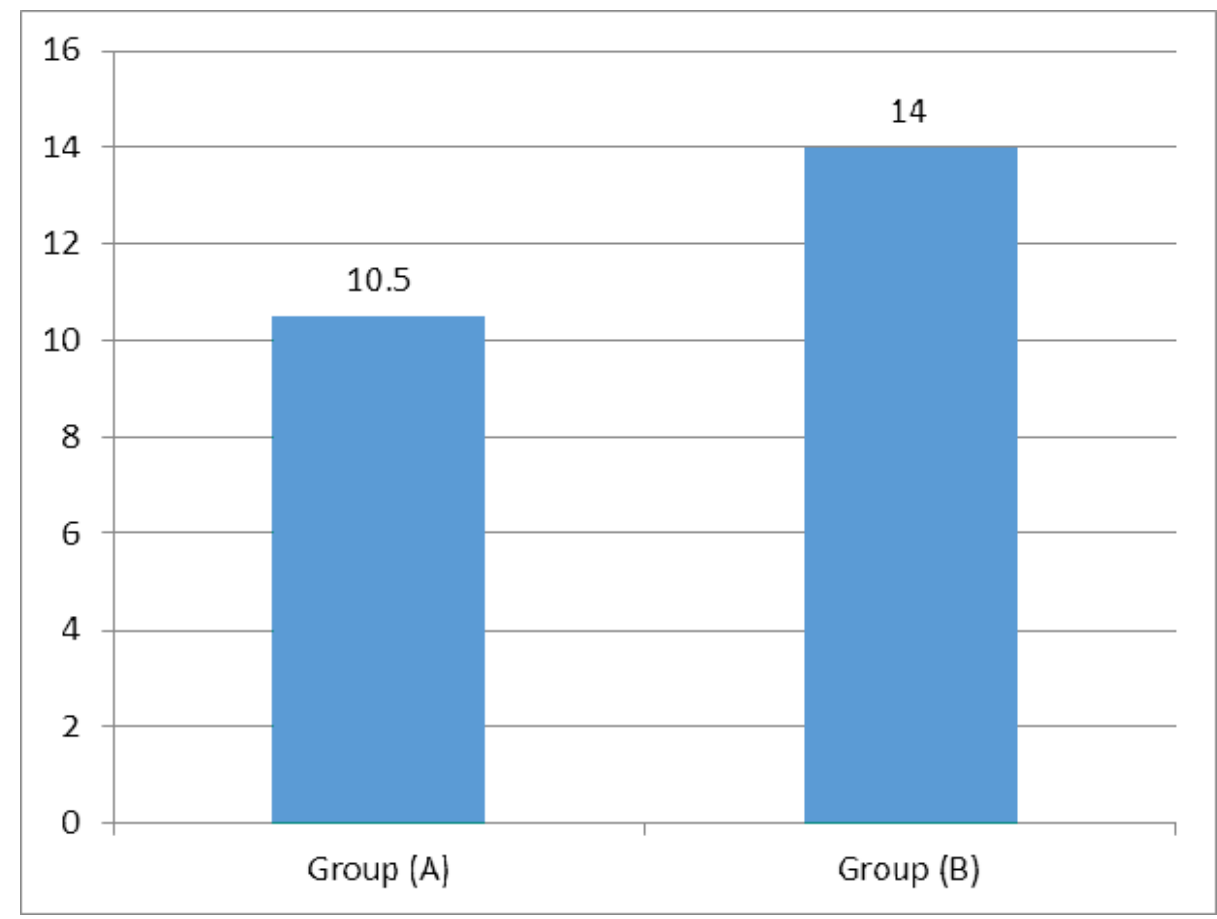

Graph 3: An overall comparison between the mean number of lymph nodes retrieved in both open and laparoscopic groups.

In Table 4 the mean number of lymph nodes retrieved in laparoscopic group was compared to that in case of open group.

In laparoscopic procedures, more lymph nodes were retrieved with a statistically significant manner expressed by $p$-value $=0.019$.

\section{Discussion}

Laparoscopic colo-rectal surgery has now evolved from being accepted only for benign colo-rectal diseases to apply for malignant colo-rectal diseases not only with the same efficacy compared to open surgery but also with all advantage of laparoscopy. Now, whenever laparoscopic surgery is feasible, it is the operation of choice. ${ }^{10,11}$

This study was designed to assess the lymph nodes harvested during both open and laparoscopic colectomy in patients with Lt. sided colorectal cancer taking into consideration the still ongoing argument about the adequacy of samples obtained laparoscopically.

Several factors affected the numbers of retrieved LNs on colorectal cancer including types of surgical resection and surgeon experience, furthermore patient age younger than 65 years may have more LNs numbers also male gender and Rt. sided cancer colon. Also the sites and size of the tumors may affect the number of LNs retrieved. ${ }^{12,13}$

In this study there is no statistically significant difference between open and laparoscopic groups as regards age, gender tumors size and sites.

In this study, the procedures were done with the same surgical team to exclude the factors of surgeon experience affecting the number of LNs retrieved. 
Also we standardized the techniques of surgery especially laparoscopic one, by meticulous dissection of the mesocolon and mesorectum under direct magnified vision, adopting no-touch technique.

One of the most important factors affecting the number of LNs retrieval is the pathologist and the technique used for detection of the LNs in the specimen. ${ }^{13,14}$

So we were in contact with the same pathology team to unify the technique of LNs examination and detection.

It has been suggested that at least 12 lymph nodes should be removed to ensure adequate resection. A recent study ${ }^{15}$ that documented available data for laparoscopic versus open colectomy showed that both procedures commonly yield about thirteen lymph nodes. Assessment of 5-year survival after laparoscopic colectomy for tumors in the left and right colon by Jacob and Salky ${ }^{16}$ showed that the mean harvest of ten lymph nodes was much the same as that with open colectomy.

In a metanalysis by Aziz et al., ${ }^{17} 17$ studies showed no significant difference in the involved radial margin or number of LNs harvested between laparscopic and open approaches for rectal cancer surgery, the same results in Lord et al. ${ }^{18}$ study.

In this study, by taking the number 12 of LNs there is no statistically significant difference between both open and laparoscopic groups but the mean number of LNs harvested in laparoscopic group was statistically significant than in open group, 14 versus 10.5 respectively ( $p$ value 0.019 ).

El-Gazzaz et al., ${ }^{19}$ found significant greater numbers of involved LNs in the laparoscopic group than in the open group in colorectal carcinoma.

It should not be denied that the advantage of field magnification provided by the laparoscope during the procedure made the task of more LNs harvesting easier.

The drawbacks of this study are that the limited number of patients and also the preoperative radiotherapy as a factor affecting LNs numbers are not included.

\section{Conclusion}

Laparoscopic colo-rectal surgery is gaining more popularity in cases of cancer although it is high demanding regarding training and learning curve. Laparoscopic resection of left sided colorectal cancer yields adequate samples of lymph nodes' number that are comparable to those obtained by open surgery.

\section{References}

1. Hernanz F, Revuelta S, Redondo C, Madrazo C, Castillo J, Gomez-Fleitas M: Colorectal adenocarcinoma: Quality of the assessment of lymph node metastases. Diseases of the Colon \& Rectum. 1994; 37: 373-377.

2. Goldstein NS, Sanford W, Coffey M, Layfield LJ: Lymph node recovery from colorectal resection specimens removed for adenocarcinoma: Trends over time and a recommendation for a minimum number of lymph nodes to be recovered. American Journal of Clinical Pathology. 1996; 106: 209-216.

3. Wong JH, Severino R, Honnebier MB, Tom P, Namiki TS: Number of nodes examined and staging accuracy in colorectal carcinoma. Journal of Clinical Oncology. 1999; 17: 28962990.

4. Denham JLJ, Kerstetter PC, Herrmann C: The complexity of the count: considerations regarding lymph node evaluation in colorectal carcinoma, Journal of Gastrointestinal Oncology 2012; 3: 30-33.

5. Faerden $A E$, Sjo $O H$, Bukholm $I R$, Andersen SN, Svindland A, Nesbakken A, Bakka A: Lymph node micrometastases and isolated tumor cells influence survival in stage I and II colon cancer. Dis Colon Rectum 2011; 54: 200-206.

6. Chang GJ, Rodriguez-Bigas MA, Skibber JM, Moyer VA: Lymph node evaluation and survival after curative resection of colon cancer: systematic review. Journal of the National Cancer Institute. 2007; 99: 433-441.

7. McDonald JR, Renehan AG, O'Dwyer ST, Haboubi NY: Lymph node harvest in colon and rectal cancer: Current considerations, World J Gastrointest Surg. 2012; 4: 9-19.

8. Baxter NN, Virnig DJ, Rothenberger DA, Morris AM, Jessurun J, Virnig BA: Lymph node evaluation in colorectal cancer patients: a population-based study. Journal of the National Cancer Institute. 2005; 97: 219-225.

9. Görög D, Nagy P, Péter A, Perner F: Influence of obesity on lymph node recovery from rectal resection specimens. Pathology Oncology Research. 2003; 9: 180-183.

10. Delaney, Conor $\mathrm{P}$, Neary Poul $\mathrm{C}$, Alexander G: instrumentation and setup, operative procedures. In: operative techniques in 
laparoscopic colorectal surgery, 1st edition, Lippincott Williams and Wilkins 2007; (3)5-11, (5)67-70.

11. Buunen M, Veldkamp R, Hop WC, Kuhry $E$, Jeekel J, Haglind E, et al: Survival after laparoscpic surgery versus open surgery for colon cancer: long-term outcomes of a randomized trial. Lancet Oncol. 2009; 10: 7-8.

12. Horzic $M$ and Kopljar M: Minimal number of lymph nodes that need to be examined for adequate staging of colorectal cancer--factors influencing lymph node harvest. Hepatogastroenterology. 2005; 52: 86-9.

13. Evans MD, Rees A, Stamatakis JD, Karandikar SS: Factors influencing lymph node retrieval in colorectal cancer and its effect on survival. Colorectal Disease. 2006; 8: 721-2.

14. Wright FC, Law $\mathrm{CH}$, Last $\mathrm{L}$, Khalifa $M$, Arnaout A, Naseer Z, Klar N, Gallinger S, Smith AJ: Lymph node retrieval and assessment in stage II colorectal cancer: A population-based study. Annals of Surgical Oncology. 2003; 10: 903-9.
15. Stracci F, Bianconi F, Leite $S$, Liso A, La Rosa F, Lancellotta V, van de Velde CJ, Aristei C: Linking surgical specimen length and examined lymph nodes in colorectal cancer patients. Eur J Surg Oncol. 2016; 42: 260-265.

16. Jacob BP, Salky B: Laparoscopic colectomy for colon adenocarcinoma: An 11-year retrospective review with 5-year survival rates. Surg Endosc 2005; 19: 643-649.

17. Aziz $\mathrm{O}$, Constantinides $\mathrm{V}$, Tekkis PP, Athanasiou T, Purkayastha S, Paraskeva P, Darzi AW, Heriot AG: Laparoscopic versus open surgery for rectal cancer: A meta-analysis. Annals of Surgical Oncology. 2006; 13: 413-24.

18. Lord SA, Larach SW, Ferrara A, Williamson PR, Lago CP, Lube MW: Laparoscopic resections for colorectal carcinoma. Diseases of the Colon \& Rectum. 1996; 39:148-54.

19. El-Gazzaz G, Hull T, Hammel J, Geisler D: Does a laparoscopic approach affect the number of lymph nodes harvested during curative surgery for colorectal cancer?. Surgical Endoscopy. 2010; 24: 113-8. 